\title{
Thymopoiesis, Alterations in Dendritic Cells and Tregs, and Reduced T Cell Activation in Successful Extracorporeal Photopheresis Treatment of GVHD
}

\author{
Aisling M. Flinn ${ }^{1,2}$ (D) Anna Ehrlich ${ }^{1} \cdot$ Catherine Roberts $^{1} \cdot$ Xiao Nong Wang $^{1} \cdot$ Janet Chou ${ }^{3} \cdot$ Andrew R. Gennery $^{1,2}$
}

Received: 4 December 2020 / Accepted: 9 February 2021 / Published online: 2 March 2021

(C) The Author(s) 2021

\begin{abstract}
Acute graft-versus-host disease (aGVHD) is a significant complication of allogeneic hematopoietic stem cell transplant (HSCT) and negatively affects $\mathrm{T}$ cell reconstitution. Extracorporeal photopheresis (ECP) reduces aGVHD, but the mechanisms remain incompletely understood. Our objective was to examine the impact of ECP on thymopoiesis in pediatric aGVHD and the mechanisms at a cellular and transcriptional level. Sixteen pediatric HSCT patients were recruited: 6 with ECP-treated aGVHD, 5 without aGVHD, and 5 with aGVHD treated with corticosteroids only. Thymopoiesis was evaluated by measuring naive T cells, TRECs, IL-7, and T cell receptor repertoire diversity. Regulatory T cell (Treg) enumeration and function and dendritic cell (DC) enumeration and phenotype were analyzed using flow cytometry. T cell transcriptome analysis was performed on ECP patients after treatment and responders pre- and post-treatment. Four ECP responders demonstrated thymic-dependent $\mathrm{T}$ cell recovery, and superior median naïve T cell numbers at 8 and 12 months post-HSCT compared to the aGVHD corticosteroid group. Increased Tregs and Treg suppressive function, reduced $\mathrm{cDC} / \mathrm{pDC}$ and $\mathrm{DC}$ co-stimulatory marker expression in ECP responders suggest upregulated peripheral tolerance; these findings were not observed in partial responders. Responder post-ECP CD3+ T cell transcriptional profile demonstrated 3333 downregulated and 364 upregulated genes, with significant downregulation of ERR $\alpha$ and $\mathrm{G} \alpha \mathrm{S}$ pathways, and reduced expression of pro-inflammatory and adhesion proteins.

Thymic function improves with successful ECP treatment. ECP reduces T cell activation and impacts peripheral tolerance via DCs and Tregs. Differences in thymic recovery, DC, and Treg cellular patterns and the T cell transcriptome were observed between ECP responders and partial responders and require further validation and investigation in additional patients.
\end{abstract}

Keywords Extracorporeal photopheresis $\cdot$ acute graft-versus-host disease $\cdot \mathrm{T}$ cell $\cdot$ thymus $\cdot$ dendritic cell $\cdot$ regulatory $\mathrm{T}$ cell

\section{Introduction}

Acute graft-versus-host disease (aGVHD) is a major complication of allogeneic hematopoietic stem cell transplantation (HSCT). T cell reconstitution is essential for a successful HSCT outcome but is negatively affected by aGVHD and its first-line treatment,

Janet Chou and Andrew R. Gennery share last authorship.

Aisling M. Flinn

Aisling.flinn@ncl.ac.uk

1 Translational and Clinical Research Institute, Newcastle University, Newcastle upon Tyne, UK

2 Great North Children's Hospital, Newcastle upon Tyne, UK

3 Division of Immunology, Boston Children's Hospital, Harvard Medical School, Boston, MA, USA corticosteroids [1-6] (Fig. S1). Corticosteroid-refractory disease often requires additional immunosuppressive agents creating a precarious balance between controlling aGVHD and the risk of infection and relapse.

Extracorporeal photopheresis (ECP) is an alternative therapy for aGVHD with a well-established clinical efficacy and safety profile $[7,8]$. ECP involves collection of peripheral blood mononuclear cells (PBMC) by apheresis, exposure to 8-methoxypsoralen, and ultraviolet A radiation, followed by re-infusion of photoactivated cells into the patient. Uniquely, there are no systemic immunosuppressive effects and ECP facilitates weaning of immunosuppressive medications; therefore, ECP does not increase infection or disease relapse risk $[9,10]$. Exactly how ECP exerts its therapeutic effects is not completely understood, but several mechanisms contributing to antigen-specific immunomodulation have been proposed including apoptosis of exposed lymphocytes, differentiation 
of monocytes into dendritic cells (DC) stimulated by physical interactions within the ECP chamber, promotion of a tolerogenic DC phenotype and increased regulatory $\mathrm{T}$ cells (Treg) although many studies incorporate in vitro ECP models or animal models [11-15]. Retrospective studies also suggest that ECP can promote thymic-dependent $\mathrm{T}$ cell recovery postHSCT $[3,16]$. We previously observed that ECP-treated patients demonstrated limited thymic recovery, although ECP was commenced late in the course of aGVHD and earlier initiation may further improve thymic output [3].

We aimed to prospectively examine the impact of ECP on thymic-dependent $\mathrm{T}$ cell recovery in a pediatric cohort by quantitative (naive $\mathrm{T}$ cell and TREC enumeration) and qualitative ( $\mathrm{T}$ cell receptor (TCR) repertoire diversity) analyses. IL7 , a cytokine produced by thymic epithelial cells in response to lymphopenia [17], was measured as an indicator of functioning thymic stroma. We hypothesized that patients who respond to ECP have successful return of quantitative and qualitative thymic function. We aimed to explore ECP mechanisms in promoting immunotolerance by analysis of Tregs and DCs throughout treatment and $\mathrm{T}$ cell transcriptome analysis before and after treatment. We hypothesized that we would observe alterations in Tregs and DCs (consistent with increased peripheral tolerance) and the $\mathrm{T}$ cell transcriptome in patients with treatment progression and we would identify differences between those who respond successfully to ECP and those who fail to respond.

\section{Methods}

\section{Study Participants}

This was an observational exploratory study involving allogeneic HSCT pediatric patients who received ECP treatment for aGVHD, following initial corticosteroid treatment. In addition, two control groups were recruited; pediatric allogeneic HSCT patients who did not develop aGVHD ("no aGVHD" group) and pediatric allogeneic HSCT patients with aGVHD treated with systemic corticosteroids but who did not receive ECP ("aGVHD corticosteroid" group). Patients were excluded from recruitment to the "no aGVHD" group if they received corticosteroids for another clinical indication. Decision to treat with ECP and weaning of immunosuppression was a physician-led clinical judgment. Patients were recruited from June 2016-January 2018. All patients attended the Great North Children's Hospital, Newcastle upon Tyne, UK. Clinical data recorded included demographics, underlying diagnosis, details regarding the HSCT and conditioning regimen, immunosuppressive agents used, type of GVHD, stage, and response to ECP. Grade of aGVHD was determined using the modified Glucksberg criteria. The NIH Consensus scoring system was used for ECP patient 5 with lung involvement [18]. Ethical approval was granted by the South Eastern Scotland Research Ethics Committee (16/SS/0019/ AM03). Written informed consent was obtained from all patients or their legal guardians.

ECP was administered on 2 consecutive days weekly for the first 9 weeks, then every 2 weeks for 7 weeks, every 3 weeks for 4 weeks and monthly thereafter until treatment cessation, although some patients deviated from this protocol based on judgment of the attending physician. One ECP cycle was defined as two ECP procedures over two consecutive days. ECP was delivered using the CELLEX® System (Mallinckrodt Pharmaceuticals, NJ, USA). Patients were designated "ECP responders" if they completed ECP treatment with GVHD resolution and weaning of immunosuppression. Patients were designated "ECP partial responders" if they remained on ECP with partial clinical improvement.

For the ECP group, blood was taken on day 1 of each cycle, and at 4,8 , and 12 months post-HSCT. For the control groups, blood samples were taken at 4,8 , and 12 months post-HSCT. There were two missing samples at 8 months and two at 12 months follow-up in the "no aGVHD" group. In the "aGVHD corticosteroid" group, there was one missing sample at 8 months follow-up. There were no missing samples in the ECP group. Due to more limited sample volumes from the control groups, analyses were confined to naïve $\mathrm{T}$ cells, DCs, and Tregs.

\section{Flow Cytometry}

For enumeration of cell absolute counts and frequencies, whole blood was stained with fluorochrome-conjugated antibodies in Trucount ${ }^{\circledR}$ tubes (BD Biosciences) and incubated for $20 \mathrm{~min}$ before adding $900 \mu \mathrm{l}$ of red blood cell lysis buffer. For enumeration of naive $\mathrm{T}$ cells $\left(\mathrm{CD} 3^{+} \mathrm{CD} 4^{+} \mathrm{CD} 45 \mathrm{RA}^{+} \mathrm{CD} 31^{+}\right)$, Tregs $\left(\mathrm{CD} 3^{+} \mathrm{CD} 4^{+} \mathrm{CD} 25^{\mathrm{hi}} \mathrm{CD} 127^{\mathrm{lo}}\right)$, and activated $\mathrm{T}$ cells $\left(\mathrm{CD}^{+}{ }^{+} \mathrm{CD} 4^{+} \mathrm{HLA}-\mathrm{DR}^{+}\right)$, the following antibodies were used (BD Biosciences): CD45-APC (HI30), CD3-Pe-Cy7 (SK7), CD4-PE (RPA-T4), CD45RA-BUV737 (HI100), CD31-APC Cy7 (WM59), HLA-DR-BUV395 (G46-6), CD127-BV421 (HIL-7R-M2), and CD25-FITC (M-A251) (Fig. S2). For DC enumeration (conventional DCs, cDCs; $\mathrm{CD} 45^{+} \mathrm{CD} 3^{-} \mathrm{CD} 34^{-} \mathrm{CD} 14^{-} \mathrm{DR}^{+} \mathrm{CD} 4^{+} \mathrm{CD} 16^{-} \mathrm{CD} 11 \mathrm{c}^{+}$and $\mathrm{CD} 11 \mathrm{c}^{-} \mathrm{CD} 123^{+}$plasmacytoid DCs, pDCs), the following antibodies were used (BD Biosciences unless otherwise stated): CD3-FITC (UCHT1), CD4-PE (RPA-T4), CD16-PE-Dazzle (3G8, Biolegend), CD123-PerCP-Cy5.5 (7G3), CD45-AF700 (H130, Biolegend), CD34-APC-Cy7 (581, Biolegend), CD11c-BV421 (B-ly6), HLA-DR-V500 (G46-6), CD14BV650 (M5E2) (Fig. S3). Data were collected using the Fortessa X-20 flow cytometer (BD Biosciences).

For DC phenotype analysis, PBMCs were prepared by density-gradient centrifugation using Lymphoprep ${ }^{\circledR}$ solution (STEMCELL Technologies) and incubated with the 
following antibodies (Biolegend unless otherwise stated): CD3-AF700 (SK7), CD19-AF-700 (HIB19), CD20-AF700 (2H7), CD14-BV650 (M5E2), CD11c-BV711 (3.9), HLADR-BUV395 (G46-6, BD Biosciences), CD16-PECF594 (3G8), CD123-BV785 (6H6), CD80-PE (L307.4, BD Biosciences), CD83-BV421 (HB15e, BD Biosciences), CD86-FITC (2331, BD Biosciences), and DAPI viability dye (Fig. S4). Data were collected using the BD FACSymphony flow cytometer (BD Biosciences). Median fluorescence intensity (MFI) was measured for CD80, CD83, and CD86 expression and the median value of the ECP responders $(n=4)$ and control groups $(n=3$ in each) was calculated. Flow cytometry data were analyzed using the FlowJo software (BD Biosciences).

\section{Treg Suppression Assay}

Patient PBMCs were stained with CD4-PE (RPA-T4), CD14BV650 (M5E2), CD127-BV421 (HIL-7R-M21), CD25-FITC (M-A251), and DAPI, and CD $25^{\text {hi }} \mathrm{CD} 127^{\text {lo }}$ Tregs were sorted using the FACS-Fusion Sorter (BD Biosciences). Monocytes were isolated from healthy control PBMCs using a MACS separation system (Miltenyi Biotec) according to the manufacturer's instructions. DCs were then generated by incubation of the isolated monocytes in RF-10 media with IL-4 and GMCSF for 6 days followed by a further 24-h culture with $0.1 \mu \mathrm{g} / \mathrm{ml}$ LPS. Treg suppression capacity was measured in a co-culture system in which a CellTrace Violet ${ }^{\mathrm{TM}}$ (CTV) (ThermoFisher)-labeled effector T cells (Teffs) were cultured with allogeneic DCs (10:1 Teff to DC ratio, both from healthy controls) in the presence of ECP patient Tregs (4:1 Teff to Treg ratio). After 5 days, the frequency of proliferating Teff cells (CTV low) was detected using flow cytometry (BD Biosciences) (Fig. S5) at 3 time points of ECP treatment (early, mid, and late/end). Co-culture without Tregs served as control.

\section{TREC Quantification}

T cell receptor excision circle (TREC) quantification was performed using a real-time PCR instrument (7900HT Fast RealTime PCR System, Applied Biosystems) as previously described [19]. A standard curve was generated by cloning of plasmid TREC/TRAC DNA kindly supplied by Sottini et al [19] DNA was purified from $5 \times 10^{6}$ PBMCs using the QIAamp ${ }^{\circledR}$ DNA Blood Mini Kit (Qiagen). The following primers and probes were used (Integrated DNA Technologies): TREC forward primer 5'-CAC ATC CCT TTC AAC CAT GCT-3', TREC reverse primer 5'-TGC AGG TGC CTA TGC ATC A-3', TREC probe 5'-FAM-ACA CCT CTG GTT TTT GTA AAG GTG CCC ACT-TAMRA-3', TRAC forward primer 5' TGG CCT AAC CCT GAT CCT CTT-3', TRAC reverse primer 5'-GGA TTT AGA GCT TCT CAG CTG GTA CAC-3' and TRAC probe 5'-FAM-TCC CAC AGA TAT CCA GAA CCC TGA CCC-TAMRA-3'. Data were analyzed using Sequence Detection Systems software version 2.4 (Applied Biosystems) and results were recorded as the number of TRECs per $1 \mathrm{ml}$ of blood.

\section{T Cell Receptor Repertoire Analysis}

T cell receptor (TCR) diversity was evaluated using complementarity-determining region 3 (CDR3) spectratyping. RNA was extracted from PBMCs using the RNeasy® Mini Kit (Qiagen), quantified using a NanoDrop® ND-1000 spectrophotometer (LabTech), and converted to cDNA using the High-Capacity cDNA Reverse Transcription Kit (Applied Biosystems). The TCR $\beta$ variable region was amplified using twenty-three V $\beta$ primers (Fig. S6) followed by a run-off reaction with FAM-labeled C $\beta$ primer and CDR3 fragment length analysis by capillary electrophoresis using the 3130 Genetic Analyzer (ThermoFisher). Data were analyzed using Peak Scanner (Applied Biosystems). Using healthy control samples, a scoring system was developed to define electropherograms as normal, abnormal, or highly abnormal (Fig. S7). Gaussian distributions were a subjective description of each $\mathrm{V} \beta$ family to demonstrate the visual change in the TCR repertoire, rather than a statistical description.

\section{Serum IL-7 Quantification}

Serum IL-7 was quantified using the Quantikine ${ }^{\circledR}$ enzymelinked immunosorbent assay (R\&D Systems) as per the manufacturer's instructions. Optimal density was measured using a Multiskan Ascent ${ }^{\circledR}$ plate reader (ThermoFisher) and data were analyzed by Ascent ${ }^{\circledR}$ software (ThermoFisher). Elevated IL-7 levels were defined as $>9.8 \mathrm{pg} / \mathrm{ml}$, as determined by the manufacturers.

\section{Whole Transcriptome Sequencing}

Transcriptional analysis was performed on three ECP responders (patients 1,2, and 4) and two partial responders (patients 5 and 6) pre- and post-ECP. Patients' $\mathrm{CD}^{+} \mathrm{T}$ cells were purified by magnetic positive selection (Miltenyi Biotec), followed by RNA isolation with the RNeasy Micro Kit (Qiagen). cDNA was synthesized from 10 ng of total RNA using SuperScript ${ }^{\mathrm{TM}}$ VILO $^{\mathrm{TM}}$ cDNA Synthesis Kit (ThermoFisher). The Ion AmpliSeq Transcriptome Human Gene Expression Kit was utilized to generate barcoded libraries per the manufacturer's protocol and sequenced using an Ion S5TM system. Differential gene expression analysis was performed using the ampliSeqRNA plugin (ThermoFisher). Pathway analysis was done using Ingenuity Pathway Analysis (Qiagen). 


\section{Data Analysis and Statistics}

Longitudinal changes in naive T cells, TRECs, IL-7, TCR repertoire, DCs, and Tregs were measured over the course of ECP treatment. Naive $\mathrm{T}$ cell number, $\mathrm{cDC} / \mathrm{pDC}$ ratio, and Treg number and frequency were compared with the control groups at 4, 8, and 12 months post-HSCT. Numerical data are reported as medians with ranges and mean values with error bars. Differences in median values were analyzed using the Kruskal-Wallis test, with a $p$ value $<0.05$ being significant. Data were analyzed using GraphPad Prism.

\section{Results}

\section{Patient Clinical Characteristics}

Sixteen pediatric patients were recruited. There were 6 patients in the ECP group with steroid-refractory aGVHD and 5 patients in each of the "no aGVHD" and "aGVHD corticosteroid" control groups. A summary of the clinical characteristics and details of aGVHD diagnoses and management are provided in Tables 1 and 2 respectively.

This was the first HSCT for all patients and none received donor lymphocyte infusions. Median age at HSCT was lowest in the no aGVHD group (4.3 years) and highest in the ECP group (7.7 years). The majority of patients in each group received serotherapy and one patient from the ECP group and one from the aGVHD corticosteroid group received total body irradiation (14 Gy). Patients in the aGVHD corticosteroid group had grade 2 skin aGVHD and received treatment with topical and systemic corticosteroids, along with continuation of aGVHD prophylaxis.

\section{ECP Responders}

ECP patients 1-4 had gut or skin aGVHD with a maximum grade of 2-3. All were refractory to corticosteroids; patient 4 also had cytomegaloviremia. Median time from HSCT to ECP commencement was 48 days (range 39-124 days). All patients had complete resolution of aGVHD with successful weaning of immunosuppression.

\section{ECP Partial Responders}

Patients 5 and 6 demonstrated partial clinical improvement. Patient 5 initially developed corticosteroid-responsive skin aGVHD, followed by pneumonitis, which partially improved with corticosteroids and infliximab, alongside antimicrobial, and antifungal therapies. Thoracic computerized tomography (CT) demonstrated bronchiolitis obliterans with an obstructive pulmonary function test (PFT) pattern (FEV1 $33 \%, \mathrm{FEV} 1 / \mathrm{FVC} 0.63$ ). Lung biopsy was not performed due to poor clinical condition and ECP was started leading to initial clinical improvement. Upon weaning of ECP to four weekly and corticosteroids to $0.1 \mathrm{mg} / \mathrm{kg}$ at cycle 30 , patient 5 developed liver aGVHD (biopsy confirmed). Weekly ECP and high dose corticosteroids were re-initiated and sirolimus was started, leading to normalization of bilirubin, and respiratory status remained stable (FEV1 34\%, FEV1/FVC 0.63, persistent exertional dyspnea). Patient 5 was considered to have overlap syndrome, with features of aGVHD present but lung involvement distinctive of chronic GVHD (cGVHD) (NIH score 3), although no other cGVHD features were present. Patient 6 developed cough and dyspnea with a restrictive PFT pattern (FEV1 35\%, FEV1/FVC 0.91) day +39 post-HSCT. Chest CT demonstrated diffuse pulmonary nodularity and lung biopsy identified active mild $\mathrm{CD}^{+}$lymphocytic bronchiolitis, consistent with partially treated aGVHD. No infectious causes were identified. Due to steroid dependency, ECP was commenced leading to PFT improvement (FEV1 69\%, FEV1/FVC 0.98). Patient 6 had no other aGVHD organ involvement and no features of cGVHD.

\section{Thymic-Dependent T Cell Recovery}

All patients exhibited low naive T cells and TRECs, and abnormal TCR repertoires at commencement of ECP regardless of timing post-HSCT, indicating poor thymic output. Increased naive $\mathrm{T}$ cells and TRECs, and an inverse relationship with IL-7, was observed with treatment progression in ECP responders. (Fig. 1a-c, Fig. S8). This coincided with resolution of clinical aGVHD, weaning of immunosuppression, and decreased activated $\mathrm{T}$ cell frequency (Fig. S9). Improvement in TCR diversity illustrated qualitative $\mathrm{T}$ cell improvement (Fig. 1d-e, Table S1). These results indicate thymic-dependent $\mathrm{T}$ cell recovery during ECP treatment. In contrast, partial responders 5 and 6 demonstrated no thymicdependent $\mathrm{T}$ cell recovery 2 years post-HSCT and $44 \mathrm{ECP}$ cycles, and 1 year post-HSCT and 21 ECP cycles respectively. An inverse relationship with IL-7 was not observed (Fig. 1f $-\mathrm{j}$, Fig. S8).

To examine how thymic-dependent $\mathrm{T}$ cell recovery in the ECP responders compared with the normal trajectory postHSCT, results were compared with the no aGVHD and aGVHD corticosteroid groups at 4, 8, and 12 months following HSCT (Fig. 1k-n). Thymic-dependent $\mathrm{T}$ cell recovery was superior in the no aGVHD group at each time point measured. At 4 months post-HSCT, naive T cell numbers were similar between ECP responders and the aGVHD corticosteroid group; however, at 8 and 12 months thymic-dependent $\mathrm{T}$ cell recovery was superior in the ECP responder group. These results highlight the negative impact of aGVHD and corticosteroids on thymic recovery. 
Table 1 Summary of patient characteristics. Conditioning was described as myeloablative (MA) if cyclophosphamide was used in combination with busulfan or with total body and cranial irradiation, reduced toxicity MA if cyclophosphamide was used in combination with fludarabine, and reduced intensity conditioning (RIC) if fludarabine and treosulfan were used, with or without additional thiotepa

\begin{tabular}{|c|c|c|c|}
\hline & ECP group, $N=6$ & $\begin{array}{l}\text { No aGVHD group, } \\
N=5\end{array}$ & $\begin{array}{l}\text { aGVHD } \\
\text { corticosteroid group, } \\
N=5\end{array}$ \\
\hline \multicolumn{4}{|l|}{ Age at HSCT (years) } \\
\hline Median & 7.7 & 4.3 & 6.6 \\
\hline Range & $4.1-13$ & $0.6-17.8$ & $1.5-15$ \\
\hline \multicolumn{4}{|l|}{ Gender } \\
\hline Male & $4(66.7 \%)$ & $2(40 \%)$ & $2(40 \%)$ \\
\hline Female & $2(33.3 \%)$ & $3(60 \%)$ & $3(60 \%)$ \\
\hline \multicolumn{4}{|l|}{ Underlying diagnosis } \\
\hline Immune deficiency & $\begin{array}{l}2(33.3 \%), \text { STAT3 GOF, } \\
\text { CTLA4 deficiency }\end{array}$ & $\begin{array}{l}3 \text { (60\%), } \\
\quad \text { Nijmegen-breakage } \\
\text { syndrome, CGD, SCID }\end{array}$ & $\begin{array}{l}3 \text { (60\%), hyper IgD } \\
\text { syndrome, } \\
\text { STAT3 GOF, } \\
\text { CGD }\end{array}$ \\
\hline Malignancy/hematological & $\begin{array}{l}4(66.7 \%), \text { relapsed } \\
\text { AML } \times 2, \text { relapsed } \\
\text { ALL, high-risk AML }\end{array}$ & $\begin{array}{l}2(40 \%), \text { severe } \\
\text { congenital } \\
\text { neutropenia, severe } \\
\text { aplastic anemia }\end{array}$ & $\begin{array}{l}2 \text { (40\%), high-risk } \\
\text { ALL, AML }\end{array}$ \\
\hline \multicolumn{4}{|l|}{ HSCT source } \\
\hline $\mathrm{BM}$ & $4(66.7 \%)$ & $4(80 \%)$ & $2(40 \%)$ \\
\hline PBSC & $2(33.3 \%)$ & $1(20 \%)$ & $3(60 \%)$ \\
\hline \multicolumn{4}{|l|}{ HSCT donor } \\
\hline Sibling/MFD & $3(50 \%)$ & $3(60 \%)$ & 0 \\
\hline MUD & $3(50 \%)$ & $1(20 \%)$ & $4(80 \%)$ \\
\hline Haploidentical & 0 & $1(20 \%)$ & $1(20 \%)$ \\
\hline \multicolumn{4}{|l|}{ HLA Matching } \\
\hline $10 / 10$ & $6(100 \%)$ & $4(80 \%)$ & $2(40 \%)$ \\
\hline$<10 / 10$ & 0 & $1(20 \%)$ & $3(60 \%)$ \\
\hline \multicolumn{4}{|l|}{ Conditioning } \\
\hline MA & $4(66.7 \%)$ & 0 & $2(40 \%)$ \\
\hline Reduced toxicity MA & 0 & $1(20 \%)$ & 0 \\
\hline RIC & $2(33.3 \%)$ & $4(80 \%)$ & $3(60 \%)$ \\
\hline TBI & $1(16.7 \%)$ & 0 & $1(20 \%)$ \\
\hline Serotherapy & $4(66.7 \%)$ & $4(80 \%)$ & $5(100 \%)$ \\
\hline \multicolumn{4}{|l|}{ GVHD prophylaxis } \\
\hline $\mathrm{CSA} / \mathrm{MMF}$ & $2(33.3 \%)$ & $3(60 \%)$ & $2(40 \%)$ \\
\hline CSA alone & $4(66.7 \%)$ & $1(20 \%)$ & $2(40 \%)$ \\
\hline None & 0 & $1(20 \%)$ & $1(20 \%)$ \\
\hline
\end{tabular}

$B M$ bone marrow, $P B S C$ peripheral blood stem cells, $M F D$ matched family donor, $M U D$ matched unrelated donor, $C S A$ cyclosporin, $M M F$ mycophenolate mofetil, $T B I$ total body irradiation, STAT3 GOF signal transducer and activator of transcription 3 gain-of-function, $C G D$ chronic granulomatous disease, CTLA4 cytotoxic T lymphocyte antigen 4, $A M L$ acute myeloid leukemia, $A L L$ acute lymphoblastic leukemia

\section{Dendritic Cell Subsets and Phenotype}

We next sought to understand mechanisms by which ECP mitigates aGVHD activity. Plasmacytoid DC numbers increased with treatment in responders (Fig. S10), with an overall decline in $\mathrm{cDC} /$ $\mathrm{pDC}$ ratio indicating a relatively higher increase in $\mathrm{pDCs}$ compared to cDCs (Fig. 2a), a population shown to mediate aGVHD tolerance and facilitate engraftment [20]. In contrast, the cDC/ pDC ratio increased with treatment in partial responder 5 and remained persistently low in partial responder 6 (Fig. 2b, c).
To decipher the potential influence of aGVHD and corticosteroids on this $\mathrm{cDC} / \mathrm{pDC}$ pattern, we compared ECP responder $\mathrm{cDC} / \mathrm{pDC}$ ratios at 4,8 , and 12 months post-HSCT with the control groups (Fig. $2 \mathrm{~d}-\mathrm{e}$ ). Median $\mathrm{cDC} / \mathrm{pDC}$ ratio was highest in the aGVHD corticosteroid group at each timepoint post-HSCT. Although the range of values and lack of statistical significance indicate the need for analysis in additional patients to ascertain the validity of these findings, lower $\mathrm{cDC} / \mathrm{pDC}$ values in the ECP responders, particularly at 4 (all ECP responders on treatment) and 8 months (3 ECP 
Table 2 Details of patients with aGVHD treated with ECP. Overall grade of aGVHD was determined using the modified Glucksberg criteria. Therapies in italics denote continued aGVHD prophylaxis

\begin{tabular}{|c|c|c|c|c|c|c|}
\hline \multicolumn{7}{|c|}{ ECP group } \\
\hline Patient & $\begin{array}{l}\text { GVHD organ } \\
\text { involvement } \\
\text { (max stage) }\end{array}$ & $\begin{array}{l}\text { Max } \\
\text { aGVH- } \\
\text { D grade }\end{array}$ & $\begin{array}{l}\text { Treatment } \\
\text { (excluding } \\
\text { ECP) }\end{array}$ & Reason for ECP & $\begin{array}{l}\text { Time from HSCT -ECP } \\
\text { (days) }\end{array}$ & $\begin{array}{l}\text { ECP outcome, number } \\
\text { of ECP cycles }\end{array}$ \\
\hline $\mathrm{P} 1$ & GIT (3), skin (2) & 3 & $\mathrm{CS}, C S A, \mathrm{IFX}$ & CS refractory & 55 & Complete response, 24 \\
\hline $\mathrm{P} 2$ & GIT (3), skin (2) & 3 & $\mathrm{CS}, C S A, \mathrm{IFX}$ & CS refractory & 39 & Complete response, 21 \\
\hline $\mathrm{P} 3$ & GIT (3) & 3 & $\begin{array}{l}\mathrm{CS}, C S A^{*} \\
\quad M M F, \mathrm{IFX}\end{array}$ & CS refractory & 124 & Complete response, 20 \\
\hline $\mathrm{P} 4$ & Skin (3) & 2 & $\begin{array}{l}\mathrm{CS}, C S A^{*}, \\
\quad M M F, \mathrm{IFX}\end{array}$ & $\begin{array}{l}\text { CS refractory, } \\
\text { CMV } \\
\text { viraemia }\end{array}$ & 40 & Complete response, 16 \\
\hline P5 & $\begin{array}{l}\text { Skin (3), liver (2), } \\
\text { Lung (NIH score } \\
\text { 3) }\end{array}$ & 3 & $\begin{array}{l}\mathrm{CS}, C S A \\
\quad M M F, \mathrm{IFX} \\
\quad \mathrm{BUD}\end{array}$ & CS refractory & 173 & $\begin{array}{l}\text { Normalization of bilirubin, } \\
\text { stable respiratory status } \\
\text { (PFTs: FEV1 34\%, } \\
\text { FEV1/FVC 0.63), persistent } \\
\text { exertional dyspnea, } 44 \text { (ongoing) }\end{array}$ \\
\hline P6 & Lung & - & $\begin{array}{l}\text { CS, CSA, } \\
\text { BUD }\end{array}$ & CS dependency & 142 & $\begin{array}{l}\text { Improvement in PFTs; FEV1 } \\
35 \% \text {, FEV1/FVC 0.91 pre-ECP } \\
\text { to FEV1 69\%, FEV1/FVC 0.98, persis- } \\
\text { tent exertional dyspnea, } 21 \text { (ongoing) }\end{array}$ \\
\hline \multicolumn{7}{|c|}{ aGVHD corticosteroid group } \\
\hline Patient & $\begin{array}{l}\text { aGVHD organ } \\
\text { involvement } \\
\text { (max stage) }\end{array}$ & Max grade & Treatment & & & Outcome \\
\hline $\mathrm{P} 1$ & Skin (3) & 2 & \multicolumn{3}{|c|}{ Topical + systemic CS, CSA } & Complete response \\
\hline $\mathrm{P} 2$ & Skin (3) & 2 & \multicolumn{3}{|c|}{ Topical + systemic CS } & Complete response \\
\hline P3 & Skin (3) & 2 & \multicolumn{3}{|c|}{ Topical + systemic CS, CSA, MMFs } & Complete response \\
\hline P4 & Skin (3) & 2 & \multicolumn{3}{|c|}{ Topical + systemic CS, CSA } & Complete response \\
\hline P5 & Skin (3) & 2 & \multicolumn{3}{|c|}{ Topical + systemic CS, CSA, $M M F$} & Complete response \\
\hline
\end{tabular}

BUD budesonide (inhaled), $C M V$ cytomegalovirus, $C S$ corticosteroids, CSA cyclosporin, CSA* CSA later changed to tacrolimus, FEV1 forced expiratory volume in one second, $F V C$ forced vital capacity, $I F X$ infliximab, $M M F$ mycophenolate mofetil, $P F T$ pulmonary function tests

responders on treatment and one recently completed treatment) post-HSCT, support an ECP-induced effect, rather than a consequence of corticosteroid use or aGVHD.

Conventional DC and pDC expression of co-stimulatory markers CD80, CD86, and CD83 was measured to examine the stage of DC maturation, an important determinant of DC immune regulatory or stimulatory capacity. We observed reduced expression of co-stimulatory markers in the ECP responders (Fig. 2f-g) in comparison to expression in 3 patients from each control group at 4 months post-HSCT, indicating a more immature or tolerogenic DC phenotype at the time points measured. In contrast, co-stimulatory marker expression was higher with occasional high MFI peaks in partial responder 5 (Fig. S10).

\section{Regulatory T Cells}

Tregs increased steadily in the ECP responders from approximately cycle 10 onwards (Fig. 3a). Responder Treg frequency increased during treatment; however, this fluctuated, without a consistent trend (Fig. 3b). Partial responder 5 demonstrated a decline in Treg number and frequency and partial responder 6 demonstrated low Treg numbers throughout and frequency mostly within the normal range (Fig. 3c, d).

In comparison to the control groups, Tregs were similar at 4 and 8 months post-HSCT, but higher in the no aGVHD group, followed by ECP responding group at 12 months (Fig. 3e, Fig. S11). Interestingly, the frequency of Tregs was highest in the aGVHD group at each time point (Fig. 3f).

Effector T cell (Teff) proliferation decreased mid-ECP treatment in the responders, indicating increased Treg suppressive capacity (Fig. 3g). Teff proliferation increased at the end of treatment in 3/4 responders indicating a reduction in Treg function at this time point but was not associated with aGVHD recurrence. In the partial responders, Teff proliferation initially increased but decreased later during treatment. 


\section{T Cell Transcriptome Analysis}

Having identified differences in thymopoiesis and DC and Treg patterns, we explored differences in the $\mathrm{CD}^{+} \mathrm{T}$ cell transcriptional signature following treatment. Compared to the partial responders, ECP responders had 26 downregulated and 24 upregulated genes ( $>1.5$-fold difference in expression, FDR $<0.05$ ) with significant enrichment of genes in pathways important in Teff metabolism (Fig. 4a, b). Specifically, expression of genes important for lipid metabolism and localization, lipid-protein complex remodeling, and glycolysis were downregulated in responder $\mathrm{T}$ cells compared to partial responders after treatment (Fig. 4c, d). To identify pathways most affected by ECP treatment, we performed whole transcriptome analysis on $\mathrm{CD}^{+} \mathrm{T}$ cells from ECP responders before and after ECP treatment. $\mathrm{CD}^{+} \mathrm{T}$ cells after treatment had 3333 downregulated and 364 upregulated genes with at least a 2-fold difference in expression compared to before treatment (FDR $<0.05$, Fig. $4 \mathrm{e}$ ), enriched in pathways related to estrogen-related receptor alpha (ERR $\alpha)$ signaling, $G \alpha S$ signaling, cytokines, and cellular adhesion and diapedesis (Fig. $3 f-j$ ). ERR $\alpha$ and $G \alpha S$ signaling pathways are involved in Teff activation and function. Downregulated cytokine genes included those associated with aGVHD pathogenesis $[21,22]$. Downregulation of genes involved in cellular adhesion and diapedesis corresponds to the clinical resolution of inflammation observed in the ECP responders at the end of treatment.

\section{Discussion}

We show that ECP responding patients exhibit qualitative and quantitative thymic-dependent $\mathrm{T}$ cell recovery, likely due to

\section{ECP Responder}

a

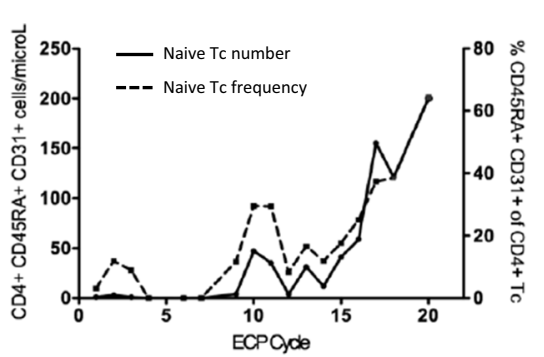

b

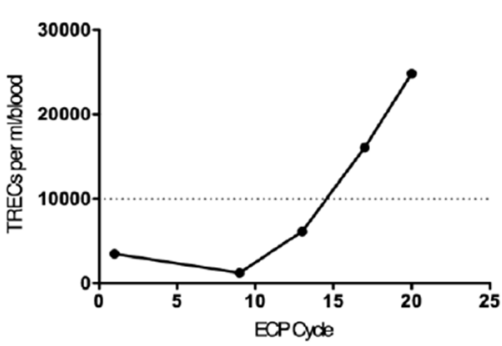

g

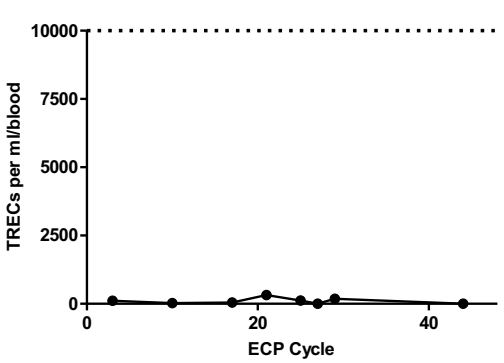

c

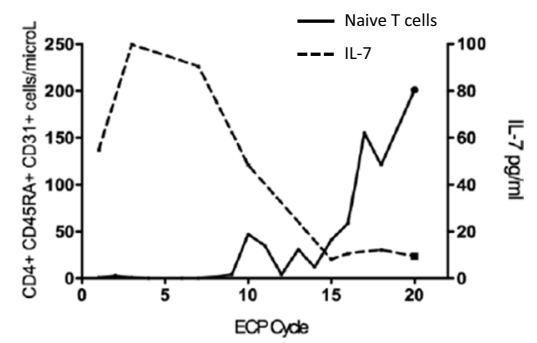

h

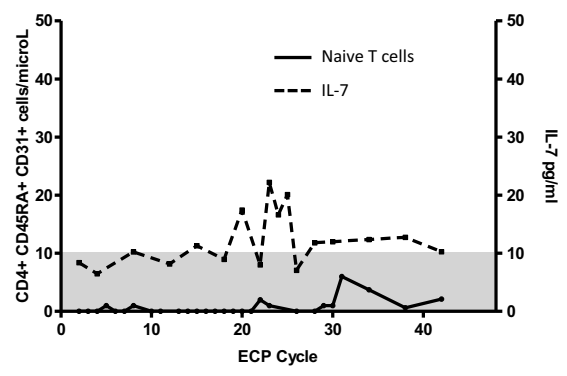

Fig. 1 In the ECP responders (example shown is patient 3), a increased frequency (dotted line) and number (continuous line) of $\mathrm{CD} 4{ }^{+} \mathrm{CD} 45 \mathrm{RA}^{+} \mathrm{CD} 31^{+}$-naive $\mathrm{T}$ cells and b TRECs (dashed line represents the upper end of the normal range for age) were observed. $\mathrm{c}$ An inverse relationship between serum IL-7 (dotted black line) and naive $\mathrm{T}$ cells (continuous line) was seen. $\mathbf{d}$, e Evaluation of the TCR repertoire indicates qualitative $\mathrm{T}$ cell improvement post-ECP as demonstrated by all TCR V $\beta$ families present with a normal Gaussian distribution, compared to pre-ECP when several non-Gaussian families were seen with multiple monoclonal peaks. Partial responder 5 demonstrated $\mathbf{f}$ ongoing negligible number (continuous line) and frequency (dotted line) of naive $T$ cells and g TRECs. h Increased IL-7 (dotted line) was not sustained and an inverse relationship with naive $\mathrm{T}$ cells (continuous line) was not evident. $\mathbf{i}, \mathbf{j}$ Qualitative $\mathrm{T}$ cell improvement was not observed with a persistently abnormal TCR repertoire later in the course of ECP. $\mathbf{k}$ Comparison of median numbers (with range) of naive T cells at 4,8 , and 12 months postHSCT demonstrate fastest thymic-dependent $\mathrm{T}$ cell recovery in patients with no aGVHD or additional immune suppression. Median naive T cell number was superior in the ECP responder group compared to the aGVHD corticosteroid group at 8 and 12 months post-HSCT. Differences between the groups were not statistically significant ( $p$ value $=0.25$ ). $\mathbf{I}-\mathbf{n}$ Mean numbers of naive $\mathrm{T}$ cells (error bars indicating $\mathrm{SEM})$ at 4,8 , and 12-months post-HSCT respectively demonstrate a similar pattern with highest numbers in patients with no aGVHD 


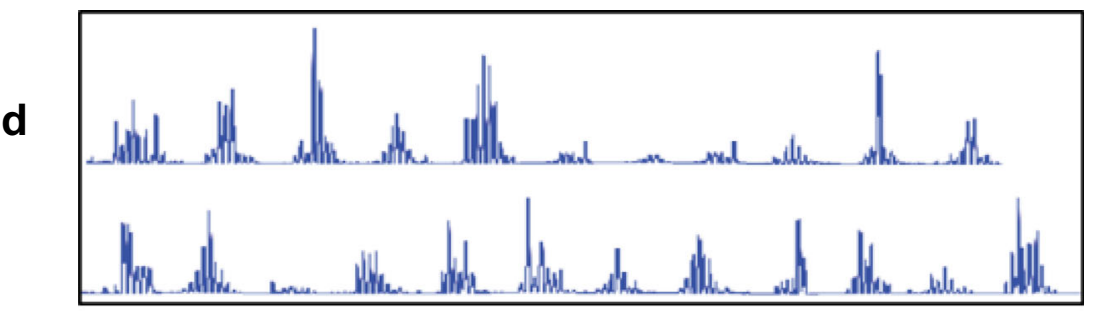

ECP responder TCR spectratype pre ECP

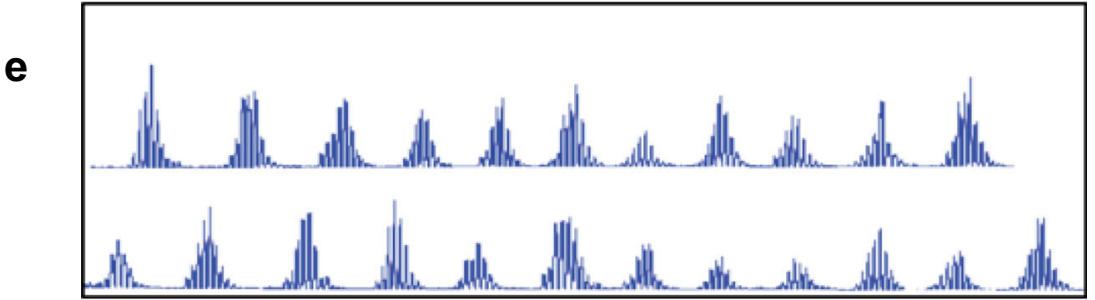

ECP responder TCR spectratype post ECP
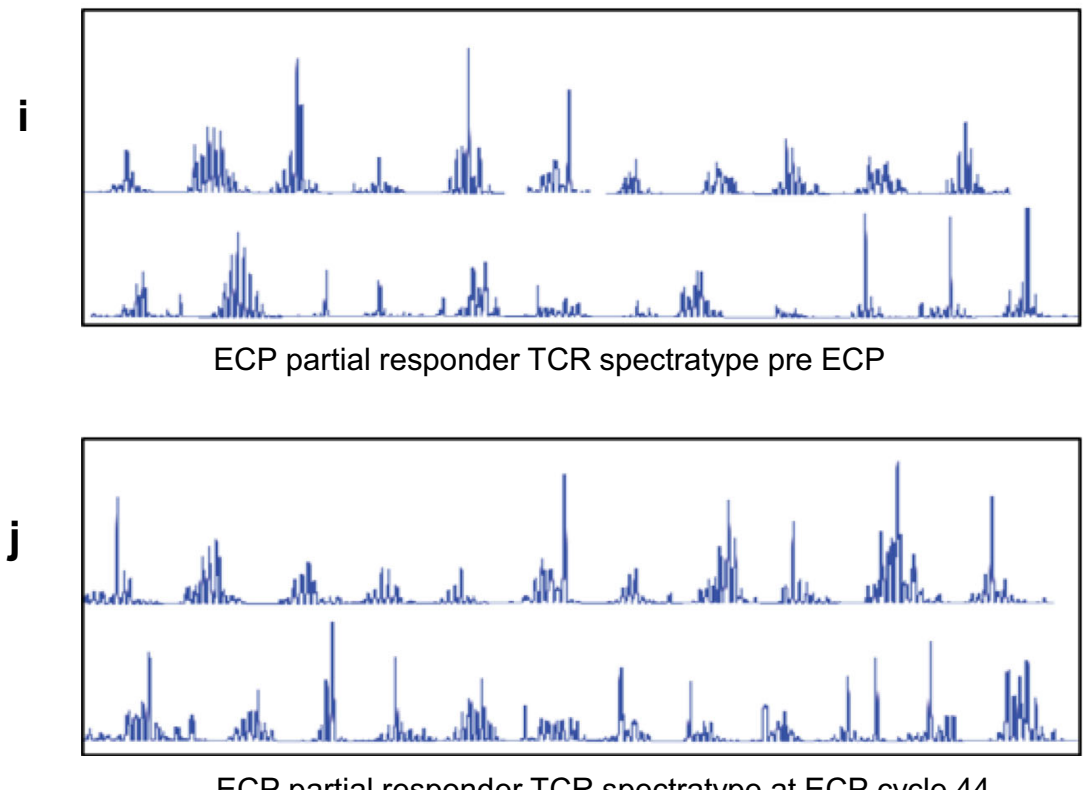

ECP partial responder TCR spectratype at ECP cycle 44

Fig. 1 (continued)

reduced aGVHD activity and immunosuppression, reinforcing previous observations $[3,16]$, and supporting the use of ECP as a "thymic-sparing" therapeutic strategy in aGVHD to facilitate $\mathrm{T}$ cell reconstitution. In addition, the slower rate of thymicdependent $T$ cell recovery in the aGVHD corticosteroid group highlights the negative influence of prolonged corticosteroids and the need to develop alternative "thymic-sparing" approaches.

Importantly, partial ECP responders did not demonstrate thymic recovery, at least in the time frame post-HSCT analyzed in this study. Increased IL-7 production in response to lymphopenia suggests the presence of functioning thymic epithelial cells; failure to mount IL-7 production as observed in patients 5 and 6 suggests thymic dysfunction which may reflect ongoing active thymic aGVHD and/or irreparable thymic damage. Although unclear if this is a permanent immune outcome, it raises the important question of whether multiple/ prolonged insults to the thymus can cause irreversible damage. Contributing factors may include longer corticosteroid exposure, slower weaning of immunosuppression, and later 


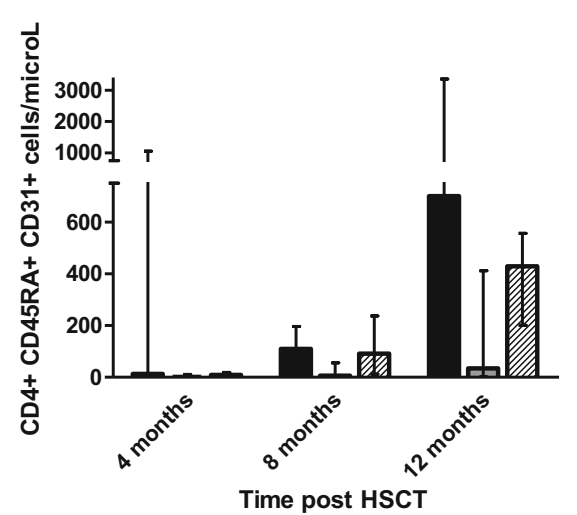

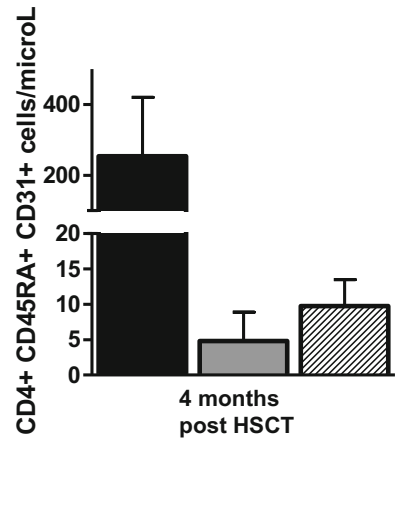

m

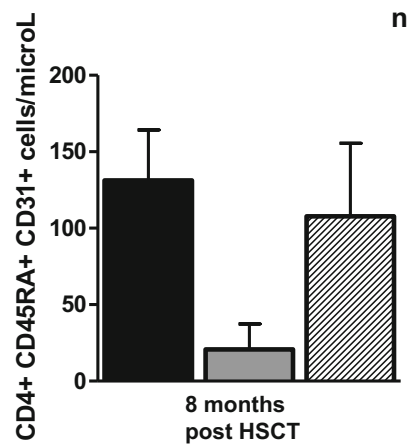

No aGVHD
aGVHD Corticosteroids
ECP Responders n

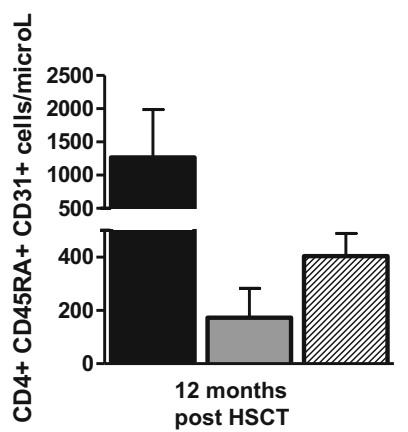

Fig. 1 (continued)

ECP initiation. Patients 5 and 6 commenced ECP 173 and 142 days after HSCT respectively, in contrast to a median of 48 days in the responders, supporting previous reports that earlier ECP may produce better outcomes [23] and suggesting that limiting insult exposure may permit faster recovery of thymic function. Investigation in additional patients is needed, and in adult patients who exhibit continued but reduced thymopoiesis associated with aging [24].

Previous studies indicate a key role played by DCs and Tregs in the immunomodulating mechanisms of ECP. We demonstrate changes in DC subsets and phenotype in ECP responders supporting an immunotolerant environment and identified differences with partial responders. Comparison with control groups provide insight into the potential mechanisms of ECP independent of the impact of corticosteroids and aGVHD, but analysis in additional patients from all groups is required to confirm the findings from this small cohort. A decline in the $\mathrm{cDC} / \mathrm{pDC}$ ratio in aGVHD treatment with ECP was described by Shiue et al [25] although how this shift to encourage $\mathrm{pDC}$ development occurs is not yet known.
Reduced co-stimulatory molecule expression indicates an immature tolerogenic DC phenotype shown to be protective against aGVHD and may contribute to reduced aGVHD activity due to inadequate co-stimulatory help [26]. While these results support a potential effect of ECP on DCs, gaps remain in our knowledge regarding their function and further examination should include functional testing such as cytokine production and $\mathrm{T}$ cell proliferative response.

Our data demonstrate increasing Treg numbers and increased Treg suppressive capacity mid-ECP treatment in responders. Increasing Tregs coinciding with renewed naive $\mathrm{T}$ cell output and without a corresponding increase in frequency suggest this incline is attributable to immune reconstitution and egress of thymic-derived Tregs. However, activated Tregs may be primarily located in sites of tissue inflammation, particularly in the early stage of ECP treatment. Examination of Tregs in aGVHDaffected tissue and specifically measuring $\mathrm{CD} 45 \mathrm{RA}^{+} \mathrm{CD} 31^{+}$ Tregs would be valuable to elucidate Treg patterns and origin [27]. Certain Treg subpopulations are associated with greater suppressive capacity, which could account for the increased 

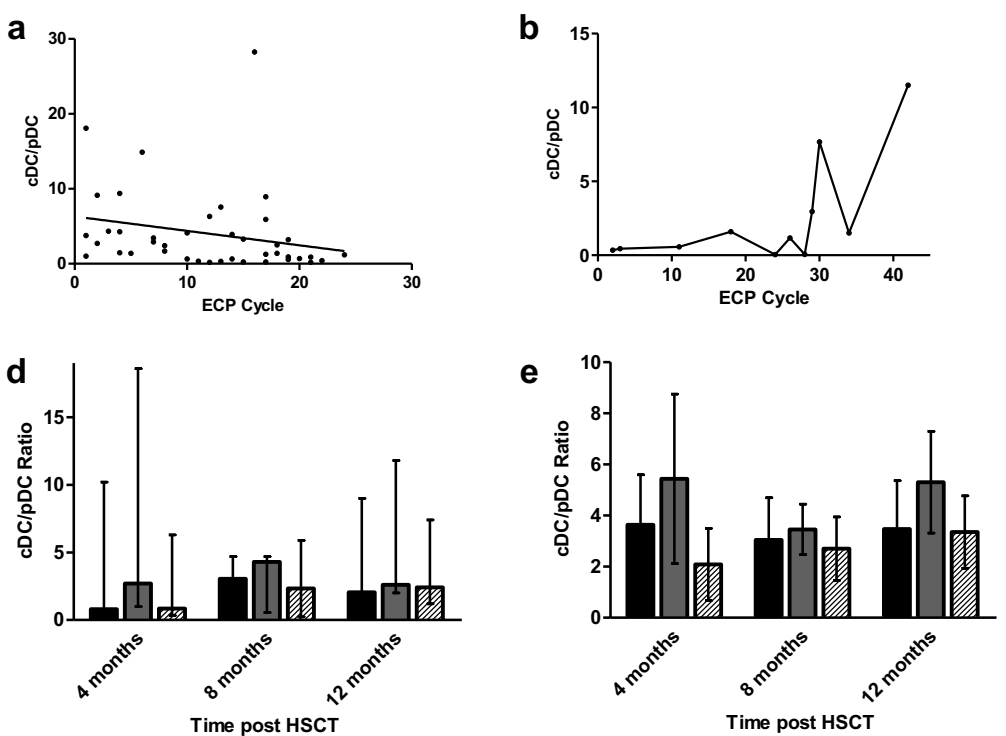

pDC CD86
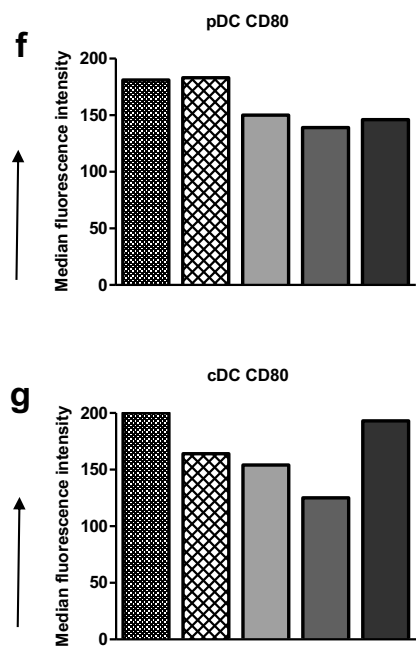

cDC CD86

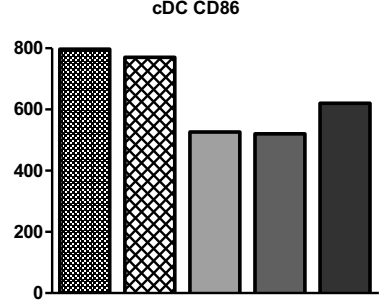

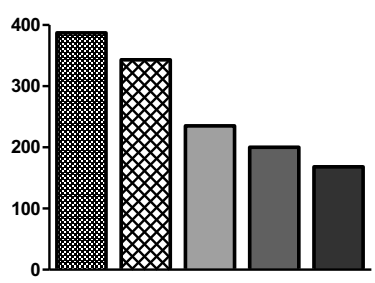

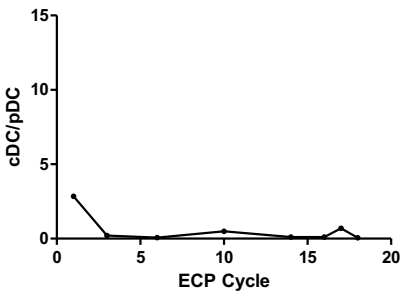

pDC CD83

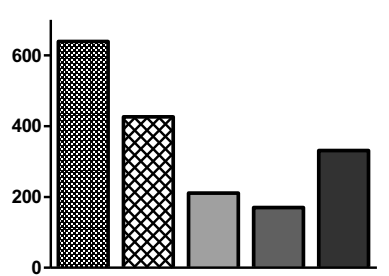

CDC CD83

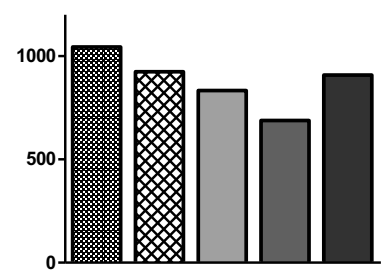

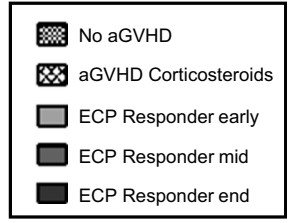

aGVHD corticosteroid group at each time point measured. Differences between the groups were not statistically significant ( $p$ value $=0.07)$. e A similar pattern was observed in the mean $\mathrm{cDC} / \mathrm{pDC}$ ratios (error bars indicating SEM) of each group. $\mathbf{f}, \mathbf{g}$ Median MFI of CD80, CD86, and CD83 expression of the ECP responders $(n=4)$ at 3 time points during treatment (early, middle, and end) was lower compared to that measured in three patients from each control group at 4 months post-HSCT
Treg suppressive function observed; a more detailed Treg analysis is needed to identify if expansion of certain subsets occurs in ECP such as IL-10-producing Tr1 Tregs. Higher Treg frequencies in the aGVHD corticosteroid group and partial responder 5 may be related to longer corticosteroid exposure [28]. However, partial responder 6, who was also exposed to prolonged corticosteroids, did not demonstrate elevated Treg frequencies suggesting involvement of other factors. Further examination of the impact of corticosteroids on Tregs would help to understand the independent effect of ECP.

ECP responders exhibited significant downregulation in gene pathways important in Teff metabolism compared to partial responders, pathways essential for allogeneic Teffs driving aGVHD [29-31]. Although partial responders demonstrated some clinical progress, these data indicate that their $\mathrm{T}$ cells retain transcriptional characteristics known to be important for aGVHD. Further evaluation in ECP responders before and after treatment displayed significant changes in ERR $\alpha$ and $\mathrm{G} \alpha \mathrm{S}$ signaling pathways which have not been highlighted in prior studies of $\mathrm{T}$ cells from patients or animal models with aGVHD. ERR $\alpha$, a transcriptional regulator of cellular metabolism, increases Teff activation and proliferation by increasing expression of genes important for glycolysis and mitochondrial function $[32,33]$. ERR $\alpha$ deficiency reduces Teff 


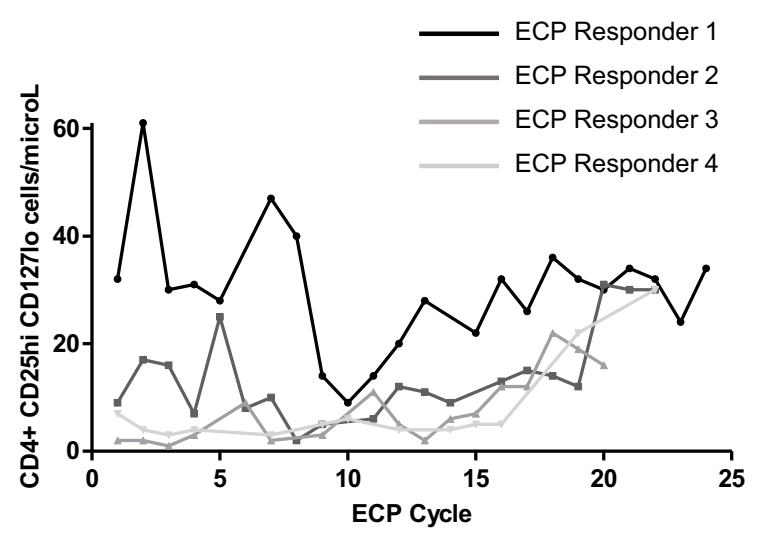

C

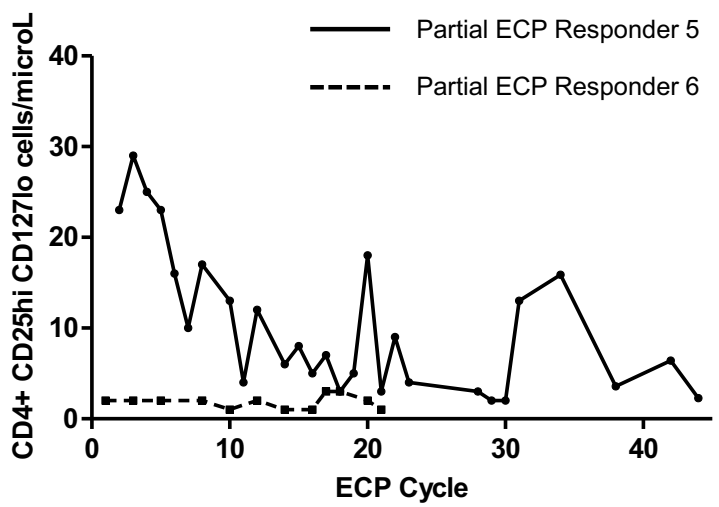

Fig. 3 a Responding ECP patients demonstrated increased Treg numbers in the latter half of treatment. $\mathbf{b}$ Treg frequency intermittently increased in the responding ECP patients, but with no upward or downward trend (normal range shaded in gray). c Partial responder 5 demonstrated a decrease in Tregs during treatment. Partial responder 6 had low Treg numbers throughout. $\mathbf{d} \mathrm{A}$ decline in Treg frequency was observed in partial responder 5 and remained largely within the normal range for patient 6. e Median numbers of Tregs (with range) were highest in the no aGVHD group followed by the ECP responders at 12 months post-

proliferation and function in experimental autoimmune encephalitis [33] and ERR $\alpha$ downregulation in the setting of ECP therapy may reduce activated Teff generation. G $\alpha \mathrm{S}$ signaling is important for Th1 and Th17 differentiation and function but dispensable in Treg generation [34]. Deletion of $\mathrm{G} \alpha \mathrm{S}$ in $\mathrm{CD}^{+} \mathrm{T}$ cells results in reduced generation of cAMP, decreased calcium flux, and the inability to induce colitis in an adoptive transfer model [34], underscoring the importance of this pathway in $\mathrm{CD}^{+} \mathrm{T}$ cell-driven inflammation. Reduced $\mathrm{T}$ cell activation via these pathways may indirectly promote naive $T$ cells and Tregs by reducing inflammation and facilitating immune reconstitution, and directly promote $\mathrm{T}$ cell differentiation towards a Treg phenotype. Further investigation is needed in additional patients to validate these findings and their functional consequences and to determine if this transcriptional signature is unique to ECP therapy.

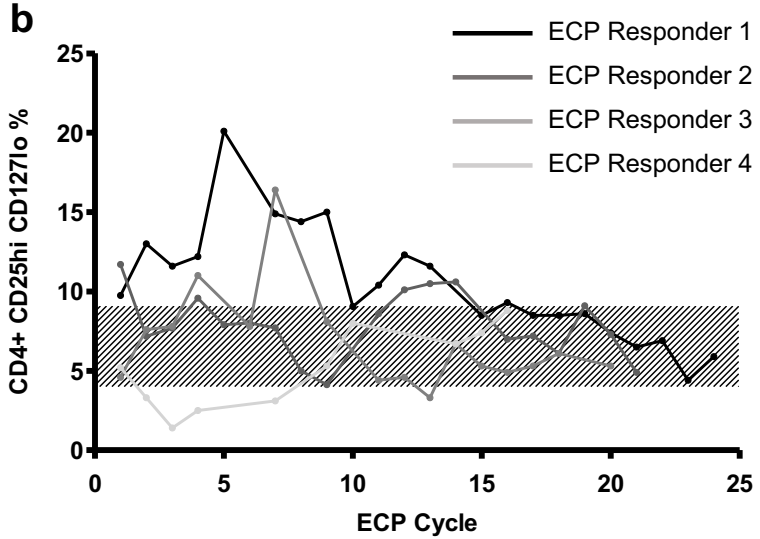

d

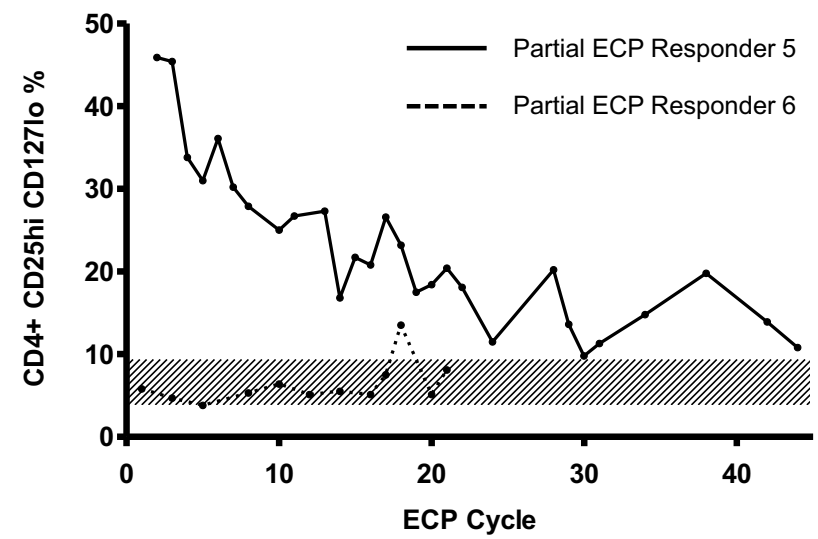

HSCT. Differences between the groups were not statistically significant ( $p$ value $=0.49)$. $\mathbf{f}$ Median (with range) Treg frequency was highest in the aGVHD corticosteroid group at each time point measured. Mean values with error bars demonstrated a similar pattern (Fig. S11). g In the ECP responders, Teff proliferation decreased mid-ECP treatment indicating increased Treg suppression compared to early in the treatment course. The arrows indicate the change (increase or decrease) from the measurement at the previous time point

The known importance of $\mathrm{T}$ cell chemotaxis in aGVHD pathogenesis [35-38] supports our observation of reduced gene expression in pathways involved in T cell migration, adhesion, and diapedesis in parallel with aGVHD resolution post-ECP. Reduced cytokine gene expression included type 1 interferons which may contribute to reduced alloreactive $\mathrm{CD}^{+}$responses. Type 1 interferon signaling is known to increase alloreactive cytotoxic $\mathrm{T}$ cell expansion, cross-present host antigens to $\mathrm{CD} 8^{+} \mathrm{T}$ cells, and activate bystander cells [39]. Further investigation at protein and functional levels, including correlation with $\mathrm{T}$ cell cytokine secretion and quantitative cellular adhesion assay would be valuable to validate these transcriptomic findings.

Study limitations include the small size and heterogeneity of the cohort. Examination of additional patients and further investigations, as outlined, are needed. Investigation of larger 
e

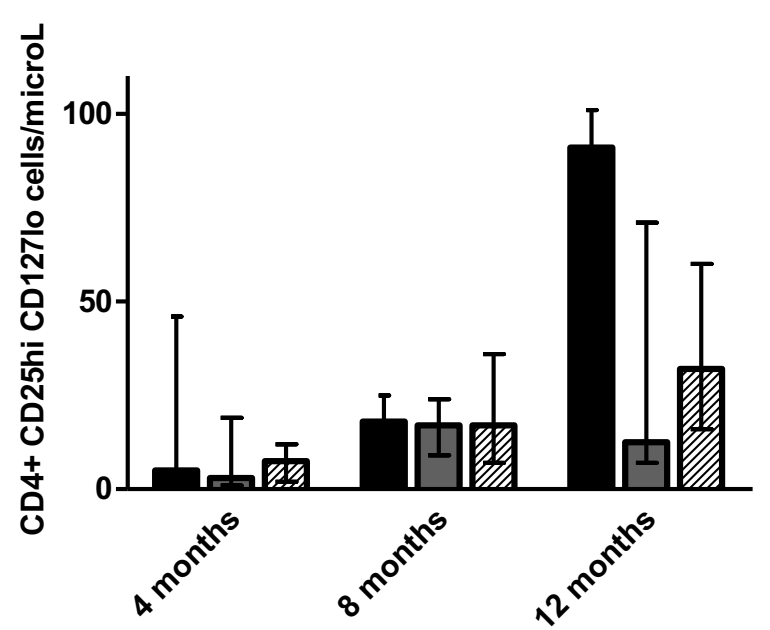

Time post HSCT f

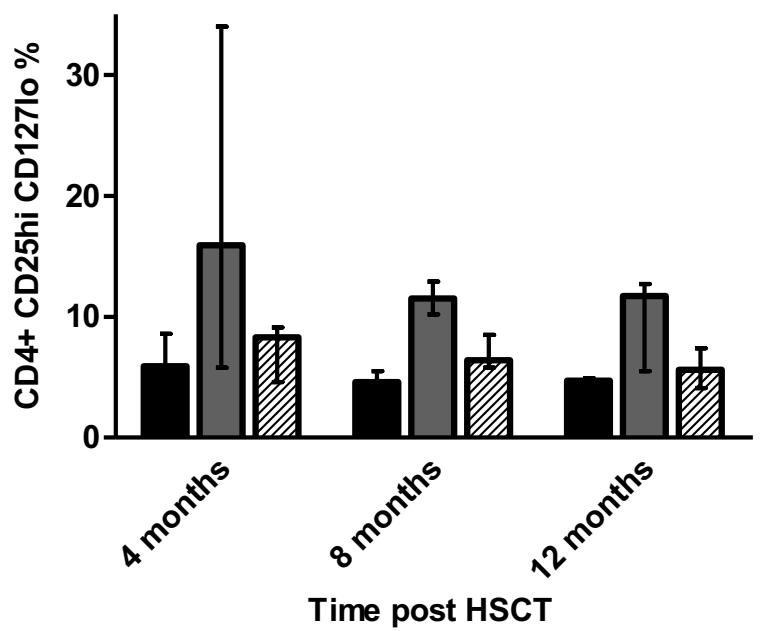

g

\begin{tabular}{|c|c|c|c|}
\hline ECP Responders & Early & Middle & End \\
\hline Patient 1 & $13.9 \%$ & $\downarrow 9.4 \%$ & $\uparrow 14.6 \%$ \\
\hline Patient 2 & $10.1 \%$ & $\downarrow 8.3 \%$ & $\uparrow 29.3 \%$ \\
\hline Patient 3 & $10.5 \%$ & $\downarrow 9.1 \%$ & $\uparrow 22.0 \%$ \\
\hline Patient 4 & $9.9 \%$ & $\downarrow 7.8 \%$ & $\downarrow 7.2 \%$ \\
\hline $\begin{array}{c}\text { ECP Partial Responders } \\
\text { (ECP ongoing) }\end{array}$ & Early & Middle & Late \\
\hline Patient 5 & $6.1 \%$ & $\uparrow 15.0 \%$ & $\downarrow 11.6 \%$ \\
\hline Patient 6 & $5.2 \%$ & $\uparrow 12.3 \%$ & $\downarrow 3.8 \%$ \\
\hline
\end{tabular}

Fig. 3 (continued)

patient and control cohorts is essential to adjust for differences in characteristics between these clinically heterogenous groups and permit clearer interpretation of results. Limited blood volumes from control groups precluded the ability to perform all analyses on these patients, which is needed for comprehensive comparison with the ECP patients.

In conclusion, these data indicate that successful ECP associates with thymopoietic recovery in children with aGVHD 


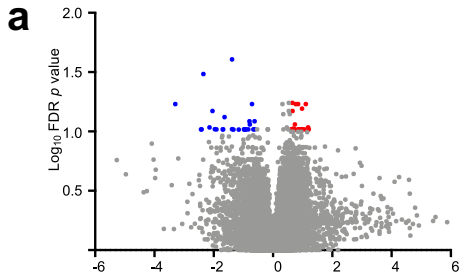

Log $_{2}$ fold change

d Lipid metabolism and localization, lipid-protein complex remodeling

Clinical Response: Partial Complete

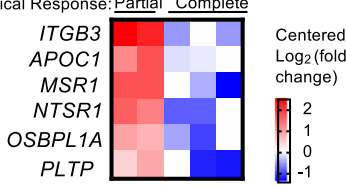

b

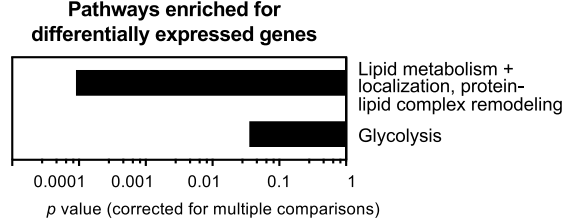

C

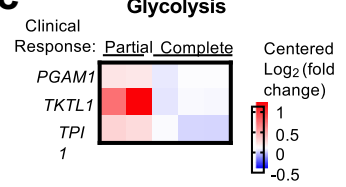

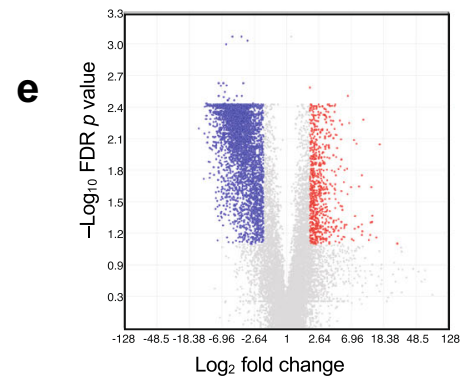

Pathways enriched for

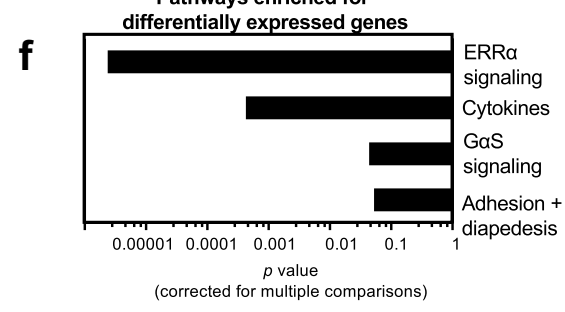

g

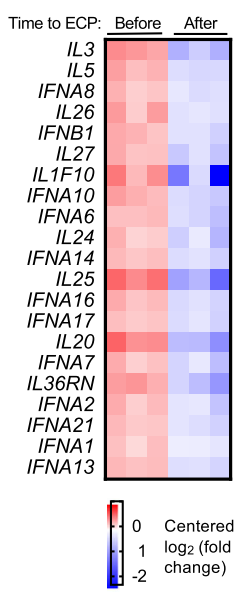

h Adhesion and diapedesis

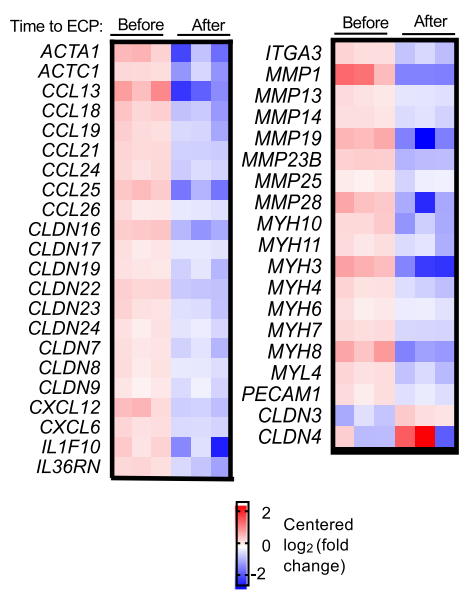

Fig. 4 a Comparison of the $\mathrm{CD} 3+\mathrm{T}$ cell transcriptional signature between ECP responders and partial responders after treatment identified 26 significantly downregulated genes (blue) and 24 upregulated genes (red) with a fold change of at least 1.5 times (FDR $p$ value $<0.1$ ). bd Significant enrichment of genes involved in Teff metabolism was identified, including genes important in lipid metabolism and localization, lipid-protein complex remodeling, and glycolysis. e $\mathrm{T}$ cell whole

and can be used as a strategy to promote immune reconstitution, especially when used early. Correlation with reconstitution of other immune cell groups and long-term follow-up is important. We demonstrate, for the first time, differences at a cellular and transcriptional level in patients with a partial ECP response. Alterations in DCs and Tregs suggest that peripheral tolerance is augmented in ECP responders and, as these patterns were not observed in partial responders, lack of upregulation could contribute to an incomplete response. We observed distinct $\mathrm{T}$ cell transcriptome changes in responders, with decreased expression of genes important for T cell activation, even in the absence of immunosuppression. As ECP is expensive, time-consuming, and requires central venous i

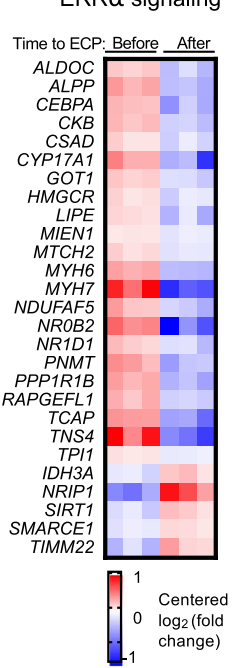

j GaS signaling

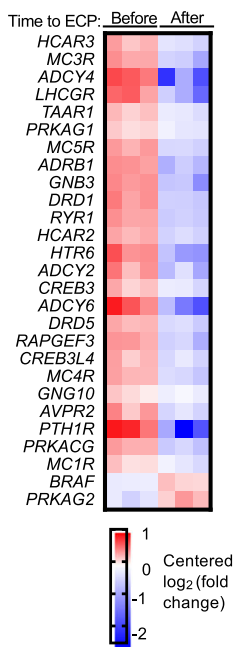

transcriptome analysis pre- and post-treatment in ECP responders identified 3333 significantly downregulated genes (blue) and 364 upregulated genes (red) with at least a two-fold difference in expression. $\mathbf{f}-\mathbf{j}$ Alterations in gene expression were seen in pathways associated with cytokines, cellular adhesion, and diapedesis, and T cell activation including estrogen-related receptor alpha (ERR $\alpha)$ signaling and $\mathrm{G} \alpha \mathrm{S}$ signaling

access in children, identifying those who will benefit from treatment is an important goal. Due to the nature of this therapy and population, investigation in large numbers is challenging. These data will direct further investigation in additional patients to validate findings and allow statistical inference. In addition, extension of investigations to include detailed Treg phenotyping, DC functional testing, and analysis of functional downstream consequences of $\mathrm{T}$ cell transcriptome changes is needed, as well as further longitudinal analysis to explore the longevity of cellular and transcriptomic alterations observed. Confirmation of specific biomarkers will assist clinical decision-making to determine who can benefit from ECP treatment. 
Supplementary Information The online version contains supplementary material available at https://doi.org/10.1007/s10875-021-00991-y.

Acknowledgments The authors thank Dr S Adams for his help with TREC and TCR repertoire analyses and Drs Sottini and Imberti for providing the TREC/TRAC plasmid. The authors also thank all the patients and families who participated in the study.

Author Contribution ARG designed the study. AMF recruited patients, collected samples, performed and analyzed immunophenotype experiments, and drafted the manuscript. JC conducted and analyzed the transcriptomic experiments and contributed to writing the manuscript. $\mathrm{AE}, \mathrm{CR}$, and XNW contributed to immunophenotype data analysis. All the co-authors agreed on the content of the manuscript.

Funding This work was supported by funding from The Bubble Foundation charity and a non-restrictive educational grant from Mallinckrodt Pharmaceuticals.

Data and Materials Availability Available upon request from the corresponding author.

Code Availability Not applicable.

\section{Declarations}

Ethics Approval Ethical approval was granted by the South Eastern Scotland Research Ethics Committee (16/SS/0019/AM03).

Consent to Participate Informed consent from all patients and/or their legal guardians.

Consent for Publication Informed consent from all patients and/or their legal guardians.

Conflict of Interest Dr. AM Flinn was partly funded by a non-restrictive educational grant from Mallinckrodt Pharmaceuticals. There are no other potential conflicts of interest to disclose.

Open Access This article is licensed under a Creative Commons Attribution 4.0 International License, which permits use, sharing, adaptation, distribution and reproduction in any medium or format, as long as you give appropriate credit to the original author(s) and the source, provide a link to the Creative Commons licence, and indicate if changes were made. The images or other third party material in this article are included in the article's Creative Commons licence, unless indicated otherwise in a credit line to the material. If material is not included in the article's Creative Commons licence and your intended use is not permitted by statutory regulation or exceeds the permitted use, you will need to obtain permission directly from the copyright holder. To view a copy of this licence, visit http://creativecommons.org/licenses/by/4.0/.

\section{References}

1. Krenger W, Hollander GA. The immunopathology of thymic GVHD. Semin Immunopathol. 2008;30(4):439-56.

2. Krenger W, Rossi S, Piali L, Hollander GA. Thymic atrophy in murine acute graft-versus-host disease is effected by impaired cell cycle progression of host pro-T and pre-T cells. Blood. 2000;96(1): $347-54$.
3. Flinn AM, Roberts CF, Slatter MA, Skinner R, Robson H, Lawrence J, et al. Thymopoiesis following HSCT; a retrospective review comparing interventions for aGVHD in a pediatric cohort. Clin Immunol. 2018;193:33-7.

4. Kong FK, Chen CL, Cooper MD. Reversible disruption of thymic function by steroid treatment. J Immunol. 2002;168(12):6500-5.

5. Purton JF, Monk JA, Liddicoat DR, Kyparissoudis K, Sakkal S, Richardson SJ, et al. Expression of the glucocorticoid receptor from the 1A promoter correlates with $\mathrm{T}$ lymphocyte sensitivity to glucocorticoid-induced cell death. J Immunol. 2004;173(6):381624.

6. Flinn AM, Gennery AR. Extracoporeal photopheresis treatment of acute graft-versus-host disease following allogeneic haematopoietic stem cell transplantation. F1000Res. 2016;5:F1000 Faculty Rev1510.

7. Das-Gupta E, Dignan F, Shaw B, Raj K, Malladi R, Gennery A, et al. Extracorporeal photopheresis for treatment of adults and children with acute GVHD: UK consensus statement and review of published literature. Bone Marrow Transplant. 2014;49(10):12518.

8. Calore E, Marson P, Pillon M, Tumino M, Tison T, Mainardi C, et al. Treatment of acute graft-versus-host disease in childhood with extracorporeal photochemotherapy/photopheresis: the Padova experience. Biol Blood Marrow Transplant. 2015;21(11):1963-72.

9. Bruserud O, Tvedt TH, Paulsen PQ, Ahmed AB, Gedde-Dahl T, Tjonnfjord GE, et al. Extracorporeal photopheresis (photochemotherapy) in the treatment of acute and chronic graft versus host disease: immunological mechanisms and the results from clinical studies. Cancer Immunol Immunother. 2014;63(8):757-77.

10. Suchin KR, Cassin M, Washko R, Nahass G, Berkson M, Stouch B, et al. Extracorporeal photochemotherapy does not suppress T- or Bcell responses to novel or recall antigens. J Am Acad Dermatol. 1999;41(6):980-6.

11. Lamioni A, Parisi F, Isacchi G, Giorda E, Di Cesare S, Landolfo A, et al. The immunological effects of extracorporeal photopheresis unraveled: induction of tolerogenic dendritic cells in vitro and regulatory T cells in vivo. Transplantation. 2005;79(7):846-50.

12. Gatza E, Rogers CE, Clouthier SG, Lowler KP, Tawara I, Liu C, et al. Extracorporeal photopheresis reverses experimental graftversus-host disease through regulatory T cells. Blood. 2008;112(4): $1515-21$.

13. Berger C, Hoffmann K, Vasquez JG, Mane S, Lewis J, Filler R, et al. Rapid generation of maturationally synchronized human dendritic cells: contribution to the clinical efficacy of extracorporeal photochemotherapy. Blood. 2010;116(23):4838-47.

14. Di Renzo M, Sbano P, De Aloe G, et al. Extracorporeal photopheresis affects co-stimulatory molecule expression and interleukin-10 production by dendritic cells in graft-versus-host disease patients. Clin Exp Immunol. 2008;151(3):407-13.

15. Maeda A, Schwarz A, Bullinger A, Morita A, Peritt D, Schwarz T. Experimental extracorporeal photopheresis inhibits the sensitization and effector phases of contact hypersensitivity via two mechanisms: generation of IL-10 and induction of regulatory T cells. J Immunol. 2008;181(9):5956-62.

16. Beattie B, Cole D, Nicholson L, Leech S, Taylor A, Robson H, et al. Limited thymic recovery after extracorporeal photopheresis in a low-body-weight patient with acute graft-versus-host disease of the skin. J Allergy Clin Immunol. 2016;137(6):1890-3.e1.

17. Shitara S, Hara T, Liang B, Wagatsuma K, Zuklys S, Hollander GA, et al. IL-7 produced by thymic epithelial cells plays a major role in the development of thymocytes and TCR gammadelta+ intraepithelial lymphocytes. J Immunol. 2013;190(12):6173-9.

18. Filipovich AH, Weisdorf D, Pavletic S, Socie G, Wingard JR, Lee SJ, et al. National Institutes of Health consensus development project on criteria for clinical trials in chronic graft-versus-host disease: 
I. diagnosis and staging working group report. Biol Blood Marrow Transplant. 2005;11(12):945-56.

19. Sottini A, Ghidini C, Zanotti C, Chiarini M, Caimi L, Lanfranchi A, et al. Simultaneous quantification of recent thymic T-cell and bone marrow B-cell emigrants in patients with primary immunodeficiency undergone to stem cell transplantation. Clin Immunol. 2010;136(2):217-27.

20. Auletta JJ, Devine SM, Waller EK. Plasmacytoid dendritic cells in allogeneic hematopoietic cell transplantation: benefit or burden? Bone Marrow Transplant. 2016;51(3):333-43.

21. Imoto S, Oomoto Y, Murata K, Das H, Murayama T, Kajimoto K, et al. Kinetics of serum cytokines after allogeneic bone marrow transplantation: interleukin-5 as a potential marker of acute graftversus-host disease. Int J Hematol. 2000;72(1):92-7.

22. Atkinson K, Vos B, Kang-Er Z, Guiffre A, Seymour R, Gillis S. Effect of in vivo administration of IL-3 and IL-6, alone and in combination with G-CSF, GM-CSF or IL-1, on haematopoiesis, graft-versus-host disease and survival after murine haematopoietic stem cell transplantation. Cytokines Mol Ther. 1995;1(1):47-55.

23. Choe HK, van Besien K. Earlier may be better: the role of extracorporeal photopheresis (ECP) as prevention of GVHD after allogeneic transplant. Leuk Lymphoma. 2018;59(2):272-3.

24. Mackall CL, Fleisher TA, Brown MR, Andrich MP, Chen CC, Feuerstein IM, et al. Age, thymopoiesis, and CD4+ T-lymphocyte regeneration after intensive chemotherapy. $\mathrm{N}$ Eng1 J Med. 1995;332(3):143-9.

25. Shiue LH, Alousi AM, Wei C, Hosing CM, Duvic M, Ni X. Augmentation of blood dendritic cells by extracorporeal photopheresis in patients with leukemic cutaneous T-cell lymphoma and graft-versus-host disease. J Invest Dermatol. 2013;133(8): 2098-100.

26. Liu E, Tu W, Law HK, Lau YL. Decreased yield, phenotypic expression and function of immature monocyte-derived dendritic cells in cord blood. Br J Haematol. 2001;113(1):240-6.

27. Miyara M, Yoshioka Y, Kitoh A, Shima T, Wing K, Niwa A, et al. Functional delineation and differentiation dynamics of human CD4+ T cells expressing the FoxP3 transcription factor. Immunity. 2009;30:899-911.

28. Braitch M, Harikrishnan S, Robins RA, Nichols C, Fahey AJ, Showe L, et al. Glucocorticoids increase CD4CD25 cell percentage and Foxp3 expression in patients with multiple sclerosis. Acta Neurol Scand. 2009;119(4):239-45.

29. Hippen KL, Aguilar EG, Rhee SY, Bolivar-Wagers S, Blazar BR. Distinct regulatory and effector $\mathrm{T}$ cell metabolic demands during graft-versus-host disease. Trends Immunol. 2020;41(1):77-91.
30. Byersdorfer CA, Tkachev V, Opipari AW, Goodell S, Swanson J, Sandquist $\mathrm{S}$, et al. Effector T cells require fatty acid metabolism during murine graft-versus-host disease. Blood. 2013;122(18): 3230-7.

31. Nguyen HD, Kuril S, Bastian D, Yu XZ. T-cell metabolism in hematopoietic cell transplantation. Front Immunol. 2018;9:176.

32. Michalek RD, Gerriets VA, Jacobs SR, Macintyre AN, MacIver NJ, Mason EF, et al. Cutting edge: distinct glycolytic and lipid oxidative metabolic programs are essential for effector and regulatory CD4+ T cell subsets. J Immunol. 2011;186(6):3299-303.

33. Michalek RD, Gerriets VA, Nichols AG, Inoue M, Kazmin D, Chang CY, et al. Estrogen-related receptor-alpha is a metabolic regulator of effector T-cell activation and differentiation. Proc Natl Acad Sci U S A. 2011;108(45):18348-53.

34. Li X, Murray F, Koide N, Goldstone J, Dann SM, Chen J, et al. Divergent requirement for Galphas and cAMP in the differentiation and inflammatory profile of distinct mouse Th subsets. J Clin Invest. 2012;122(3):963-73.

35. Portero-Sainz I, Gomez-Garcia de Soria V, Cuesta-Mateos C, Fernandez-Arandojo C, Vega-Piris L, Royg M, et al. A high migratory capacity of donor T-cells in response to the lymph node homing receptor CCR7 increases the incidence and severity of GvHD. Bone Marrow Transplant. 2017;52(5):745-52.

36. Reshef R, Luger SM, Hexner EO, Loren AW, Frey NV, Nasta SD, et al. Blockade of lymphocyte chemotaxis in visceral graft-versushost disease. N Engl J Med. 2012;367(2):135-45.

37. Eyrich M, Burger G, Marquardt K, Budach W, Schilbach K, Niethammer D, et al. Sequential expression of adhesion and costimulatory molecules in graft-versus-host disease target organs after murine bone marrow transplantation across minor histocompatibility antigen barriers. Biol Blood Marrow Transplant. 2005;11(5):371-82.

38. Chung J, Ebens CL, Perkey E, Radojcic V, Koch U, Scarpellino L, et al. Fibroblastic niches prime $\mathrm{T}$ cell alloimmunity through Deltalike notch ligands. J Clin Invest. 2017;127(4):1574-88.

39. Robb RJ, Kreijveld E, Kuns RD, Wilson YA, Olver SD, Don AL, et al. Type I-IFNs control GVHD and GVL responses after transplantation. Blood. 2011;118(12):3399-409.

Publisher's Note Springer Nature remains neutral with regard to jurisdictional claims in published maps and institutional affiliations. 